\title{
Circulação e vivência nas cidades: ser mulher, ser flâneuse
}

\author{
Luísa Antonitsch Mansilha Mello' (DD 0000-0003-3108-3796 \\ Ana Paula Pereira da Gama Alves Ribeiro2 (iD 0000-0002-6494-1470 \\ 'Serviço Social do Comércio, Rio de Janeiro, RJ, Brasil. 21060-130 \\ 2Universidade do Estado do Rio de Janeiro, Duque de Caxias, RJ, Brasil. 25065-050
}

Lon

Resumo: Neste artigo, propomos uma reflexão sobre a circulação das mulheres nas cidades, entendendo que os caminhos e as experiências nas diversas cidades grandes do mundo se diferem, levando em consideração as questões de raça e classe inseridas ao pesquisarmos essas mulheres. Encontramos o conceito da flâneuse, mulher que percorre caminhos pela cidade ao mesmo tempo em que reflete e cria durante esses trajetos, buscando de que maneira se dá a relação da mulher com as ruas da cidade e como, nessa relação, surgem mecanismos de resistência, ao trazê-lo para o âmbito da região metropolitana do Rio de Janeiro e suas especificidades.

Palavras-chave: mulheres; cidades; flâneuse; etnografia; circulação urbana.

\section{Wandering and Experiencing the City: Being a Woman, Being a Flâneuse}

Abstract: This paper reflects on women's circulation in cities. Understanding that paths and experiences differ in various large cities of the world, we researched these female wanderings considering issues of race and class. We examine the concept of the flâneuse, a woman who wanders along routes through a city while reflecting and creating along the way, to understand the relation between women and city streets, and how mechanisms of resistance emerge in this relationship, by considering it in the scope of the metropolitan region of Rio de Janeiro and its specificities.

Keywords: Women; Cities; Flâneuse; Ethnography; Urban wandering.

\section{Introdução}

O artigo que apresentamos é fruto de uma pesquisa de mestrado, desenvolvida em um programa de pós-graduação na área de educação, e dialoga com um projeto maior, a saber, "Múltiplas Imagens das Cidades: Representações no Cinema e em outras mídias", assim como com o subprojeto "As Cidades das Mulheres". A pesquisa "Mulheres, práticas de resistência cultural e ocupação simbólica: flâneuses da Baixada" foi desenvolvida entre os anos de 2016 e 2018 e tinha como proposta, em um primeiro momento, acompanhar produtoras culturais, realizadoras audiovisuais, escritoras, poetas, performers, participantes de bandas e cineclubistas em eventos nos municípios que compõem a Baixada Fluminense' (FIRJAN, 2020), na Região Metropolitana do Rio de Janeiro; entre eles, e especialmente, Nilópolis, Nova lguaçu e Duque de Caxias.

Durante a pesquisa, nove movimentos ou coletivos foram acompanhados e alguns dos eventos produzidos ou dos quais participaram foram etnografados. Naquele momento, quatro mulheres que atuam em diferentes frentes foram entrevistadas de forma mais aprofundada; estas mulheres são jovens (a mais velha tinha, na época, 33 anos), negras e brancas, moradoras e atuantes nos municípios referidos.

\footnotetext{
' A Baixada Fluminense faz parte da Região Metropolitana do Estado do Rio de Janeiro, geograficamente composta pelos municípios de Nova Iguaçu, Belford Roxo, Duque de Caxias, Japeri, Mesquita, Nilópolis, Nova Iguaçu, Queimados, São João de Meriti, Magé, Guapimirim, Seropédica, Itaguaí, Paracambi e Mangaratiba. Fonte: Sistema FIRJAN. Disponível em http://www.firjan.com.br/o-sistema-firjan/mapa-do-desenvolvimento/\#.
} 
A questão que se apresentava era que muitos daqueles eventos eram desenvolvidos e aconteciam nas ruas daquelas cidades, em espaços públicos e com intensa circulação a pé e em transportes públicos (Gabriela FERREIRA, 2018). Assim, trabalhamos o conceito de "flâneuses": aquelas que não só caminham e refletem, mas criam através desse movimento urbano, para chegar às mulheres que flanam pelas cidades da região metropolitana do Rio de Janeiro, e além de seus limites. Pesquisamos as estratégias de ocupação dos corpos femininos que estão nas ruas da Baixada Fluminense, produzindo eventos culturais, dirigindo filmes, expondo sua arte ou no próprio processo da sociabilidade.

Buscando melhor entender o campo, chegamos ao conceito de flâneur, tão acionado em contextos diversos quando se trata de ganhar os espaços das cidades.

É importante ressaltar que, no momento da pesquisa, estava se construindo todo um debate sobre certa explosão feminista (Heloísa Buarque de HOLLANDA, 2018) e de como era importante perceber a ałuação de muitas mulheres nos mais diversos campos. Se o conceito flâneur pode trazer muitos debates e desdobramentos, entendemos que havia uma atuação específica destas mulheres e uma associação e posterior generificação do conceito de flâneur, estando em curso um debate interdisciplinar posto nas últimas décadas (Régine ROBIN, 2009; Elizabeth WILSON, 1992; 2013; Nadja MONNET, 2014; Rebecca SOLNIT, 2016a; Lauren ELKIN, 2016).

Ressaltamos que neste debate não há ainda uma preocupação com a interseccionalidade (Kimberlé CRENSHAW, 1989; Carla AKOTIRENE, 2019) subjacente a determinadas questões, seja a não universalidade do 'ser mulher' ou do 'ser flâneuse', refletindo sobre os muitos marcadores sociais que se impõem no debate, assim como as distintas vivências e formas de experimentar as cidades e as próprias cidades como elas se colocam.

Em uma época de intensos debates sobre decolonialidade, assumimos os limites de se pensar as mulheres a partir de um conceito do século XIX, usualmente aplicado à vida dos homens e a outros contextos citadinos. Portanto, as possibilidades de se pensar as "flâneuses" em uma realidade de periferia urbana, em uma metrópole latino-americana, com especificidades de raça, gênero e território. Entendendo o percurso do conceito europeu, não vemos na utilização do termo "flâneuse" uma resposta, mas um caminho que é encontrado em uma busca para resolver o que se aproxima da prática. Não aprofundaremos estas questões neste momento, mas, sim, pretendemos apresentar estas primeiras aproximações sobre o ser mulher, ser flâneuse, refletindo sobre a contribuição de algumas destas autoras no que se constitui uma flâneuse.

\section{Os caminhos da flâneuse}

O que é ser flâneuse? Para responder a essa questão, retomamos a figura do flâneur. A literatura sobre o flâneur é inicialmente masculina, e a predominância dos homens nas cidades aponta para essa tendência. No entanto, trazemos aqui uma bibliografia que pensa o flâneur sob a ótica das mulheres, portando, empregando a forma feminina do termo. Buscamos entender como surgiu o conceito do flanar aplicado ao espaço das mulheres na cidade, e, em menor grau, nas ruas da Baixada Fluminense.

Vários estudos descrevem as flâneuses, a figura feminina que flana pelas cidades, sejam os escritos literários de Elkin (2016), sejam as pesquisas urbanas feitas por mulheres como Robin (2009), Solnit (2016a), Monnet (2014), Wilson (1992; 2013), entre outras.

Elkin realizou seus estudos percorrendo as cidades de Nova lorque, Paris, Veneza, Tóquio e Londres. Percorrer as cidades, para ela, é algo que lhe dá prazer: "Eu gosto de poder parar quando quero, de encostar em um prédio e fazer anotações no meu diário, ou ler um e-mail, ou enviar uma mensagem de texto, e o mundo parar quando eu faço isso" (ELKIN, 2016, p. 21, tradução nossa). Robin (2009) flanou por Nova lorque, Los Angeles, Buenos Aires, Londres e Tóquio. Monne† (2014) escreve sobre flanar como pesquisadora pelas ruas de Barcelona. Wilson (1992; 2013) escreve sobre o espaço das mulheres nas cidades de Nova lorque, Paris, Chicago, Londres, Moscou, Lusaca e São Paulo.

Compreendemos que, ao nos colocarmos na rua como pesquisadoras, também acabamos por realizar flânerie (flanância) ao percorrer cidades da Baixada Fluminense como Nilópolis, Duque de Caxias e Nova lguaçu.

Rebecca Solnit (2016a), historiadora da arte e do feminismo, refletindo sobre o caminhar, acredita que

[n]as cidades grandes, os espaços são projetados e construídos tanto quanto os lugares: andar, testemunhar, estar em público são parte do projeto e da finalidade tanto quanto comer, dormir, fazer sapatos, amor ou música nos ambientes internos. A palavra cidadão está ligada às cidades, e a cidade ideal se organiza em torno da cidadania, em torno da participação na vida pública. [...] Caminhar é só o começo da cidadania, mas é por meio dele que o cidadão ou a cidadã conhece sua cidade e outros cidadãos e realmente habita a cidade, e não uma parte dela, pequena e privatizada. Andar pelas ruas é o que une a leitura do mapa à maneira como se leva a vida, o microcosmo pessoal ao macrocosmo público; dá sentido ao labirinto circundante (SOLNIT, 2016a, p. 290-291). 
Portanto, de acordo com Solnit (2016a), explorar a cidade é se sentir cidadão, é tomar a cidade para si. Michel de Certeau (2014, p. 163) analisa o caminhar ao se propor a acompanhar alguns procedimentos que são "multiformes, resistentes, astuciosos e teimosos - que escapam à disciplina sem ficarem mesmo assim fora do campo onde se exerce, e que deveriam levar a uma teoria das práticas cotidianas, do espaço vivido e de uma inquietante familiaridade da cidade". Segundo o autor:

Essa história começa ao rés do chão, com passos. São eles o número, mas um número que não constitui uma série. [...] Sua agitação é um inumerável de singularidades. Os jogos dos passos moldam espaços. Tecem os lugares. Sob esse ponto de vista, as motricidades dos pedestres formam um desses "sistemas reais cuja existência faz efetivamente a cidade", mas "não têm nenhum receptáculo físico" (CERTEAU, 2014, p. 163).

A antropóloga Nadja Monnet (2014), em suas reflexões sobre as flanâncias femininas, retoma os escritos de autoficção da historiadora francesa Régine Robin (2009), que acredita que flanar é explorar a cidade, não somente caminhar por ela, mas captá-la em todas as suas formas. Para Robin, realizar etnografia urbana é também uma maneira de ser flâneuse:

Para Régine Robin (2009), flâneuse das megalópoles contemporâneas, trata-se de explorar a cidade em todas as direções e através de diferentes meios de locomoção, para apreendê-la plenamente. Realizar uma etnografia em um contexto urbano, seria partir em busca de urbanidade, se transformar de alguma forma em um catador ou uma catadora de pistas para se compreender aquilo que faz de uma cidade, cidade (MONNET, 2014, p. 218).

Assim como Robin (2009) aproxima o flanar da realização da pesquisa de campo, ao explorar a cidade, o ato de circular pela cidade dentro do contexto da pesquisa de campo nos mostra na prática que - antes de sermos pesquisadoras, ou ao mesmo tempo em que pesquisamos - somos mulheres realizando flanâncias. A experiência de apreender a cidade ao percorrer os espaços culturais foi traçando um caminho na pesquisa que se desvelou por meio das mulheres que vivem, que se colocam nas ruas, resistem, caminham, habitam, circulam pelos lugares dentro e fora da Baixada Fluminense (Luísa MELLO, 2018).

Pela imersão nos caminhos que fizemos durante a pesquisa de campo, circulando pelas ruas e praças das cidades, sendo apresentadas a cada personagem e realizando uma pesquisa visual e teórica junto ao trabalho de campo, fomos nos percebendo também flâneuses.

Caminhar pelas ruas da cidade é criar histórias e percepções, apreender gestos, imagens e referências; é ir em busca daquilo que identificamos e do que estranhamos, afetos e desafetos por espaços, eventos, passagens. A cidade existe como ela é porque nós existimos nela, modifica-se com a nossa mudança, e nos transformamos com ela.

\section{Sobre flanar}

Charles Baudelaire (2001) consolidou a figura do flâneur no contexto literário, um homem que vagava lentamente pelas ruas de Paris, por entre a multidão de meados do século XIX. Anos mais tarde, esse personagem foi retomado nos estudos de Walter Benjamin, que era ele mesmo um adepto das flanâncias urbanas. Segundo Paola Berenstein Jacques (2012, p. 41-42), Benjamin (2006) retomou essa figura mítica e a analisou no século XX, "em particular em Paris do segundo império segundo Baudelaire (Das Paris des Second Empire bei Baudelaire, publicado em 1938) e no livro das Passagens (Das Passagen-Werk, publicação póstuma e tardia)". Para a autora, o flâneur se desenvolve no processo de modernização das grandes cidades: "Contra a velocidade imposta pela modernidade positivista, o flâneur traz a questão da lentidão e também a da ociosidade" (JACQUES, 2012, p. 47).

Outro autor reconhecido pelo amor às ruas, João do Rio (1951), também escreveu sobre o perambular pelas ruas do Rio de Janeiro em sua obra A alma encantadora das ruas, de 1910, ligando esse percurso ora à vagabundagem, ora à reflexão e ao olhar investigativo. Para ele, "flanar" é um verbo universal, que não seria pertencente a nenhuma língua específica: "Flanar é ser vagabundo e refletir, é não ser basbaque e comentar, é ter o vírus da observação ligado ao da vadiagem [...]. Flanar é a distinção de perambular com inteligência" (RIO, 1951, p. 12).

Os tempos mudaram, e os "homens de gênio", que Benjamin diz terem sido flâneurs, assim como aquele sujeito despreocupado que flana pelas ruas de João do Rio, dão lugar a indivíduos que refletem ao flanar. De acordo com Wilson (2013), em seu artigo "O flâneur invisível", existe uma ambiguidade na figura do flâneur; muitos o veem como alguém que passeia, vagueia e observa a cidade; outros entendem que suas ações devem ser representadas de alguma forma - por meio de escritos, filmes, imagens - para serem descritas como flânerie. Para ela, a ênfase no "olhar" obscurece de maneira irônica:

O flâneur, de fato, trabalhava ao vagar ao longo da calçada ou investigava o submundo dos marginais. Obscurece, também, a enorme inquietação que o discurso sobre o flâneur expressa. 
O flâneur aparece caracteristicamente como marginal. Baudelaire alinhou-se com os marginais da sociedade, com as prostitutas, com os trapeiros, os bêbados. Não foi apenas a identificação usual de uma intelligentsia marginal com sua contrapartida de classe baixa; foi também a antecipação de Baudelaire a Benjamin e Kracauer na interpretação da sociedade em que viveu, nos termos de um processo opressivo da banalização. A sociedade inteira estava envolvida em um tipo de prostituição gigante; vendia-se tudo, e o escritor, entre todos, foi um dos que mais se prostituiu, por prostituir sua arte (WILSON, 2013, p. 57).

Para Wilson (2013), o flâneur pode ser aquele que, enquanto caminha e explora, pensa a cidade nesses processos. No itinerário do flâneur, o sentido é encontrado no caminhar, não como algo vadio, sem destino, mas algo funcional; é alguém que observa as interações sociais da cidade, o ritmo, os movimentos, buscando, com isso, o conhecimento sobre si e sobre o outro.

\section{A existência das flâneuses}

À medida que fomos nos aprofundando nos estudos das flanâncias, tivemos acesso a reflexões acerca do andar pelas cidades como mulheres pelos escritos literários da norte-americana Lauren Elkin (2016), que faz a aproximação do termo masculino flâneur para o feminino: flâneuse, a mulher andarilha que percorre as cidades e, em suas descobertas, reflete sobre o cenário urbano e seus sujeitos. Ela ressalta que essa definição não existia previamente na língua francesa e que muitos teóricos e escritores não acreditavam que pudesse existir uma figura feminina correspondente ao flâneur. As atividades e oportunidades do flanar pelas ruas da cidade eram privilégios do homem, ainda que sempre tenham existido mulheres - na arte, na fotografia, na literatura - que desafiavam imposições sociais e saíam pelas cidades para andar, observar e pesquisar.

Enquanto isso, Solnit (2016a), no livro A história do caminhar, sinaliza que poucas mulheres podiam caminhar pelas ruas, além das que exerciam a função de prostitutas, e ousar perambular era motivo suficiente para uma mulher ser considerada prostituída. Segundo a autora, até "o século XX, as mulheres raras vezes caminhavam pela cidade por prazer, e as prostitutas quase não nos deixaram registros de sua experiência" (SOLNIT, 2016a, p. 300). Assim surge a questão da flâneuse como aquela que se prostituía, pois, supostamente, seria essa a mulher que teria a liberdade de vagar pelas ruas da cidade. Para Elkin, o problema desse pensamento se insere no fato de essa "liberdade" ser controlada:

Em primeiro lugar, existiam mulheres na rua que não estavam vendendo seus corpos. E, em segundo lugar, não existia nada como a liberdade do flâneur de perambular pela rua; prostitutas não tinham liberdade de percorrer a cidade. Os movimentos delas eram estritamente controlados: em meados do século XIX havia toda a sorte de leis ditando onde e entre quais horários elas poderiam encontrar os homens. Suas vestimentas eram estritamente policiadas; elas tinham que se registrar na prefeitura e comparecer à polícia sanitária em intervalos regulares. Isso não era nenhum tipo de liberdade (ELKIN, 2016, p. 8-9, tradução nossa).

A existência das flâneuses foi invisibilizada durante muitos anos na história do caminhar pelas cidades, e foi-se construindo uma ideia do flanar contada pelos homens, por meio de uma visão masculina. Wilson (2013), ao pesquisar historicamente a relação das mulheres com as cidades, fala sobre o desconforto gerado pela presença das mulheres em lugares públicos de entretenimento e nas ruas da Europa durante o período da revolução industrial, no século XIX, o que causou uma série de discursos repressivos e moralizantes. De acordo com a autora, "de fato, o destino e o lugar das mulheres na cidade foram um caso especial de alarme e de uma ambivalência mais gerais que se estenderam através do espectro político" (WILSON, 2013, p. 44). A vida urbana foi minando a autoridade patriarcal, homens e mulheres iam para as cidades em busca de melhores empregos e salários.

Para Wilson (2013, p. 45), a prostituição era, além de uma ameaça, "uma metáfora para a desordem e o transtorno das hierarquias naturais e instituições da sociedade". Assim, foi instaurado um motivo para a instituição de leis e reformas que atingiriam todas as mulheres.

A prostituta era uma "mulher pública", mas o problema na vida urbana do século XIX era se cada mulher no novo e desordenado mundo da cidade - a esfera pública das calçadas, dos cafés e dos teatros - não era uma mulher pública e, desse modo, uma prostituta. A presença intensa de mulheres desacompanhadas - sem dono - ameaçava o poder e a "fragilidade" masculinos. Embora a classe masculina governante tenha feito de tudo para restringir o movimento das mulheres nas cidades, provou ser impossível bani-las de todos os espaços públicos. Elas continuaram a se aglomerar no centro das cidades e nos distritos industriais (WILSON, 2013, p. 46).

Enquanto isso, os homens burgueses continuavam a explorar as cidades livremente por prazer, e o crescimento dos espaços de lazer criou a figura mítica do flâneur, disposto a vagar por cafés, teatros e lojas de todo tipo. Segundo Wilson (2013, p. 47), existia a referência do flâneur como uma figura desocupada, aquele que podia esbanjar o tempo com hobbies vinculados ao movimento urbano, como observar a multidão e comprar, por isso a alusão ao homem burguês 
do final do século XIX. Entre os flâneurs, existia uma série de artistas que faziam da paisagem urbana matéria para suas obras.

Segundo Solnit (2016a), não existe a figura do flâneur - ou, como ela denomina, o flanador - longe da literatura e da idealização do personagem.

O flanador geralmente é descrito quase como um detetive em sua observação indiferente do próximo, e as estudiosas feministas debatem se houve ou poderia ter havido flanadoras, mas nenhum detetive literário encontrou e nomeou um indivíduo de verdade que se qualificasse ou fosse conhecido como flanador [...]. Ninguém satisfaz exatamente ao conceito de flanador, mas todos se envolveram em uma ou outra versão da flanagem (SOLNIT, 2016a, p. 332-333).

Segundo Wilson (2013, p. 50), Siegfried Kracauer (1981) acreditava que o flâneur havia substituído o homem boêmio, surgindo em seus primórdios como o "irônico incorrigível, observador imparcial, deslizando sobre a superfície da cidade, provando seus prazeres com curiosidade e interesse". Já Benjamin (1973, apud WILSON, 2013), prossegue a autora, "escreve sobre os modos pelos quais o flâneur, na condição de artista, vai exercer sua botânica do asfalto. Ele é o naturalista desse ambiente não natural" (WILSON, 2013, p. 50, grifos da autora).

Posto isso, Wilson (2013, p. 50) acredita que essas definições sobre o flâneur, que vão de Kracauer a Benjamin, são muito rígidas: "Griselda Pollock e Janet Wolff" admitem que, pelo menos, a algumas mulheres era permitido o acesso a certas partes do domínio público essencialmente masculinas". Assim, Wilson argumenta:

Janet Wolff não é precisa ao argumentar que as mulheres da classe média tinham sido mais ou menos consignadas ao lar nos últimos anos do século XIX, exatamente quando elas apareciam cada vez mais nos espaços públicos da cidade. Com o aumento das vagas em escritórios para mulheres, foram necessárias, por exemplo, casas de alimentação onde elas pudessem ir sozinhas e com conforto. A falta desses estabelecimentos em Londres já havia sido pressentida. Em 1852, um observador notou que as mulheres da classe operária frequentavam casas públicas, locais onde ninguém da classe média se sentia confortável. Por volta de 1870, os guias turísticos começavam a listar os locais em Londres onde as damas poderiam convenientemente almoçar quando estivessem na cidade para um dia de compra e desacompanhadas de um cavalheiro (WILSON, 2013, p. 52).

As mulheres, por mais que estivessem saindo de um período de reclusão, segundo Wilson (2013), não deixavam de ser vistas nas ruas das cidades. Aqui é importante frisar que, embora a autora concorde com Janet Wolff (1985) e a historiadora da arte feminista Griselda Pollock (1988) quando apontam "que as mulheres eram exploradas e oprimidas na cidade do século XIX" (WILSON, 2013, p. 54), Wilson diverge de seus pensamentos ao dizer que:

Se o espaço urbano é tão fundamentalmente construído segundo as diferenças de gênero que as mulheres não estão simplesmente em desvantagem, mas são, do ponto de vista da representação, excluídas ou extirpadas, ou se, mais do que isso, a cidade é um espaço contraditório e móvel do qual as mulheres podem se apropriar (WILSON, 2013, p. 54).

Assim, quando pensamos nas oportunidades e nos perigos para as mulheres na cidade, isso vai depender das comparações implicadas nesse jogo: "No século XIX e hoje, as oportunidades eram e são mais afetadas pela classe e pela afiliação étnica" (WILSON, 2013, p. 54). Acrescentamos ainda que, ao pensar no espaço das mulheres na cidade, é necessário levar em consideração de que rua, de que país e de que cidade estamos falando ou, ainda, se estamos falando de mulheres predominantemente brancas, articulando questões raciais e de classe. Não é sensato fazer generalizações sobre o flanar das mulheres tanto no século XIX como atualmente, uma vez que existem muitas inconsistências na história, como aponta Wilson:

A afirmação de Janet Wolff de que não havia flâneuses também desconsidera as escritoras do século XIX. Admite-se que elas tinham muito mais dificuldade que os homens para desempenhar o ofício. Para isso, a adoção de uma identidade masculina era uma solução. É notório o caso de George Sand, que usava vestes masculinas para poder percorrer as ruas livremente. Delphine de Girardin, romancista, poeta e dramaturga bem-sucedida com seu próprio nome, assumiu um pseudônimo masculino para escrever a coluna no jornal do marido, cujo conteúdo poderia ter sido escrito por qualquer flâneur parisiense - embora a identidade da autora fosse bem conhecida e, de tempos em tempos, ele dedicasse a coluna a polêmicas abertamente feministas (WILSON, 2013, p. 55).

\section{As flâneuses no Brasil}

Vimos até aqui que, ao colocarmos tamanho peso nas considerações preconcebidas sobre os flâneurs e no pertencimento das ruas das cidades aos corpos masculinos, deixamos de dar a devida importância à resistência da mulher a esse sistema de definições. Se a flâneuse

${ }_{2}$ Griselda Pollock: teórica que estuda os feminismos nas artes visuais, tendo desenvolvido pesquisas nas áreas de sociologia da arte, cultura e gênero. 
é aquela que circula pela cidade e a pensa, no contexto brasileiro, ela é também aquela que ocupa, produz e se faz presente nas ruas das cidades. Dessa forma, a aproximamos com o que foi colocado pelos autores Schuma Schumaher e Érico Brazil (2007) e Rachel Soihet (1997), com relação à resistência diária das mulheres pobres e escravizadas para circular pelas ruas do Brasil, diante das barreiras encontradas.

No empenho de uma reflexão sobre o flanar de mulheres no Brasil e a utilização desse conceito no contexto brasileiro, foi necessária uma digressão. Neste sentido, buscamos referências sobre as mulheres e suas presenças nas ruas das cidades nos períodos abordados na pesquisa. E, aqui, as distinções entre este flanar, e a presença e ocupação das mulheres nas ruas das cidades brasileiras, entendendo as especificidades de classe e raça imbuídas nesses contextos.

De acordo com a pesquisadora Maria Ângela D'Incao (1997), em seu artigo "Mulher e família burguesa", no início do século XIX, o Brasil ainda era um país rural e o estilo de vida da elite dominante era espelhado no da aristocracia portuguesa. Segundo a autora, no século XIX, com relação às cidades brasileiras: "Com fraca diferenciação e estratificação social, a cidade é habitada por uma população homogênea: pessoas ricas parecem não se distinguir, pela maneira de viver, de outras mais pobres, com as quais se relacionam" (D'INCAO, 1997, p. 224).

Assim, não havia muitas regras sobre a ocupação dos espaços até então. No entanto, chegou o momento em que as ruas das cidades (como Rio de Janeiro e Olinda) passaram a ser mais controladas, e muitas restrições foram impostas à população: "O espaço urbano, antigamente usado por todos em encontros coletivos, festas, mercados, convívio social, etc., começa a ser governado por um novo interesse, qual seja, 'o interesse público', controlado pelas elites governantes" (D'INCAO, 1997, p. 224-225). De acordo com D'Incao (1997, p. 226), um conjunto de ideias europeias passou a ser implementado na colônia, que era baseada na escravidão e na exploração da terra, com a presença de novos valores: "A proposta era ser 'civilizado', como eram os franceses e os europeus em geral". Dessa forma, todas as relações sociais que não eram consideradas civilizadas eram combatidas por leis e pela imprensa. Foi então que a rua passou a ser vista em oposição ao espaço privado do lar:

A mulher da elite passou a marcar presença em cafés, bailes, teatros e certos acontecimentos da vida social. Se agora era mais livre - "a convivência social dá mais liberdade às emoções" não só o marido ou o pai vigiavam seus passos, sua conduta era também submetida aos olhares atentos da sociedade (D'INCAO, 1997, p. 228).

Rachel Soihet (1997), pesquisadora da história das mulheres no Brasil, em seu artigo "Mulheres pobres e violência no Brasil urbano", afirma que, durante o período da Belle Époque (1890-1920), recaía sobre as mulheres a carga de pressões sobre o comportamento pessoal e familiar que era desejado. No entanto,

[a] organização familiar dos populares assumia uma multiplicidade de formas, sendo inúmeras as famílias chefiadas por mulheres sós. Isso se devia não apenas às dificuldades econômicas, mas igualmente às normas e valores diversos, próprios da cultura popular. A implantação dos moldes da família burguesa entre os trabalhadores era encarada como essencial, visto que no regime capitalista que então se instaurava, com a supressão do escravismo, o custo de reprodução do trabalho era calculado considerando como certa a contribuição invisível, não remunerada, do trabalho doméstico das mulheres (SOIHET, 1997, p. 362-363).

Soihet salienta a dificuldade de pesquisar as mulheres no Brasil daquele período. Somente a partir dos anos 1960, escravizados e mulheres foram considerados sujeitos da história. Para a autora, é desalentadora a situação ao buscar fontes sobre a atuação das mulheres no Brasil: "No tocante às mulheres pobres, analfabetas em sua maioria, a situação se agrava" (SOIHET, 1997, p. 364).

No entanto, ela vai em busca de processos criminais e, sobre a circulação urbana das mulheres na época, argumenta que, "[e]mbora as mulheres mais ricas fossem estimuladas a frequentar as ruas em determinadas ocasiões, nos teatros, casas de chá, ou mesmo passeando nas avenidas, deveriam estar sempre acompanhadas" (SOIHET, 1997, p. 365). A rua era tida como local de tentações e desvios e as mães pobres deveriam vigiar suas filhas, o que se tornava difícil, já que precisavam trabalhar e sair às ruas atrás de alternativas para sobreviver: "toda a sua maneira de sobreviver implicava a liberdade de circulação pela cidade, pois dependiam de um circuito ativo de informações, bate-papos, leva-e-traz, contratos verbais" (SOIHET, 1997, p. 365).

Assim, acentuou-se a repressão contra as mulheres e, como consequência, a sua resistência a continuarem circulando pelas ruas. Soihet acredita que a repressão à permanência das mulheres nas ruas se devia à tentativa de afrancesar a cidade e mostrar que éramos civilizados. Além disso, Soihet (1997, p. 366) especifica que, no "caso das mulheres, acrescentavam-se os preconceitos relativos ao seu comportamento; sua condição de classe e de gênero acentuava a incidência da violência". Assim, as mulheres mais pobres resistiam às normas impostas. A autora relembra, no trecho abaixo, a importância da circulação e permanência delas nas ruas: 
Ocorre que esse processo não se desenrolou sem uma efetiva resistência dos membros das camadas populares, inclusive da parcela feminina, que disputava, palmo a palmo, o seu direito ao espaço urbano. Deve-se ter em mente que para muito a rua assumia ares de lar onde comiam, dormiam e extraíam o seu sustento. Também era nos largos e praças que as mulheres costumavam reunir-se para conversar, discutir ou se divertir, da mesma forma que se aglomeravam nas bicas e chafarizes, não raro, brigando pela sua vez. Em grande proporção responsáveis pela manutenção da família, a liberdade de locomoção e de permanência nas ruas e praças era vital para as mulheres pobres, que cotidianamente improvisavam papéis informais e forjavam laços de sociabilidade (SOIHET, 1997, p. 366-367).

Ainda é preciso ressaltar que, antes da abolição da escravidão, já havia mulheres negras circulando pelas ruas do Brasil, nos mercados públicos e no ir e vir de seus afazeres. Segundo a pesquisadora, arquiteta e urbanista brasileira Raquel Rolnik (1989), a rua também era território ocupado pela população escravizada:

A contiguidade dos sobrados nas zonas centrais da cidade contribuía para que fosse intensa a circulação de escravos domésticos: buscando água nos chafarizes, indo ou voltando com a roupa ou os dejetos para jogar nos rios, carregando cestas perto dos mercados, transportando objetos de um ponto a outro da cidade. Em 1854, a população de São Paulo, em torno de 30 mil habitantes, era composta por oito mil escravos, quase 1/3 de sua população livre. Na cidade do Rio de Janeiro, em 1860, havia cem mil escravos para uma população total de 250 mil habitantes, 60\% dos quais envolvidos com o serviço doméstico (ROLNIK, 1989, p. 31).

Os mercados e espaços religiosos negros eram pontos de encontro das populações escravizadas e livres, segundo Rolnik (1998), e as mulheres negras nos mercados eram quituteiras, trabalhadoras que percorriam os espaços públicos da cidade. Também denominadas quitandeiras, eram participantes do cenário urbano e do mercado de trabalho feminino no período da escravidão. Conforme Schumaher e Brazil (2007, p. 61) argumentam no livro Mulheres Negras do Brasil, a origem do termo "kitanda" é quimbundo: "Em muitas sociedades africanas, a responsabilidade pela subsistência e o comércio de gêneros de primeira necessidade foram, desde os mais remotos tempos, encargos femininos".

Schumaher e Brazil (2007) salientam que o lugar do comércio era ocupado por mulheres escravizadas e também por mulheres negras que haviam sido libertas, o que leva a crer que, diante da necessidade de sobrevivência pelo trabalho, seus corpos eram vistos passando pelas ruas das cidades do Brasil.

Essa circulação pelas ruas também acarretava alguns problemas envolvendo as autoridades locais (SCHUMAHER; BRAZIL, 2007), como foi o caso de Eva Maria do Bonsucesso, escrava liberta que foi atrás de seus direitos:

\begin{abstract}
A forra Eva Maria do Bonsucesso, em julho de 181 1, armou, como fazia todos os dias, seu tabuleiro de couves e bananas na antiga rua da Misericórdia, na cidade do Rio de Janeiro. Importunada por uma cabra que comeu seus produtos, a quitandeira reagiu espancando o animal, que, para sua surpresa, pertencia ao príncipe dom Pedro. Irritado com a situação, o funcionário responsável pelo animal esbofeteou a mulher, e a questão foi parar na justiça. Após enfrentar corajosamente o processo e contar com muitas testemunhas a seu favor, Eva conseguiu meter na cadeia 0 homem branco que a agredira (SCHUMAHER; BRAZIL, 2007, p. 64).
\end{abstract}

Essas mulheres eram vistas como um perigo, uma vez que possuíam liberdade de circulação, realizando o comércio de importantes produtos para as cidades na época. De acordo com Schumaher e Brazil (2007, p. 65), "espalhadas por regiões estratégicas das cidades, elas percorriam ruas e vielas não só anunciando os mais variados produtos, mas também propalando idéias". Portanto, medidas repressivas foram criadas para restringir sua livre movimentação: em São Paulo, por exemplo, ficariam "impedidas de ultrapassar os limites da cidade, além de serem obrigadas a fechar as quitandas depois da Ave-Maria" (SCHUMAHER; BRAZIL, 2007, p. 65).

Assim, diante da reflexão sobre o espaço ocupado pelas mulheres nas ruas do Brasil, é importante ressaltar a importância dessa ocupação das ruas e das estratégias de resistência, uma vez que, como abordam os autores, essas mulheres, na condição de escravas ou alforriadas, exerciam um papel relevante não somente nas ruas das cidades, mas na própria economia do país: "De um continente ao outro, as mulheres negras movimentaram e deslocaram um mundo. Vinham e voltavam pelos seus sentimentos e saberes, transformavam memórias em rimas e maneiras de ser" (SCHUMAHER; BRAZIL, 2007, p. 65).

\title{
As flâneuses da Baixada
}

É possível verificar nos escritos de Elkin como se dá a relação das flâneuses na cidade atualmente e como elas são muito mais do que uma figura feminina correspondente ao flâneur masculino: 
Uma vez que eu comecei a procurar a flâneuse, eu avistei ela em todos os lugares. [...] Ela está indo para algum lugar ou vindo de algum lugar; ela está impregnada com os entre-lugares. [...] Ela conhece a cidade vagando pelas ruas, investigando seus cantos escuros, olhando por trás de fachadas, penetrando por pátios. Eu a encontrei usando as cidades como espaços de performance ou como lugares para se esconder; lugares para buscar fama e sucesso ou anonimato; como lugares para se libertar da opressão ou para ajudar aqueles que são oprimidos; como lugares para declarar sua independência; como locais para mudar o mundo ou para ser mudada por ele.

Eu encontrei muitas correspondências entre elas; essas mulheres leem umas às outras, e suas leituras se ramificaram externamente em uma rede tão desenvolvida, que resiste se catalogando. Os retratos que pinto aqui atestam que a flâneuse não é meramente o feminino de flâneur, mas uma figura a ser considerada e inspirada totalmente por conta própria (ELKIN, 2016, p. 22, tradução nossa).

Elkin narra o momento em que se percebe uma flâneuse, ao percorrer as ruas de Paris, muitas vezes sem saber ao certo seu destino, um andar despreocupado e facilitado pelo cenário urbano parisiense convidativo. O desafio durante a pesquisa de campo foi pensar de que maneira esse flanar feminino poderia ser aplicado às ruas das cidades da Baixada Fluminense.

Mesmo que os estudos apresentados anteriormente não tenham sido sobre os corpos femininos que percorrem as ruas das cidades da Baixada, podemos tirar muitas interseções de pensamentos. Decerto o caminhar pela Baixada não é tranquilo nem despreocupado, mas tampouco existe uma impossibilidade nesse flanar. Para as flâneuses que constituíram os sujeitos dessa pesquisa, o flanar é presente em seus cotidianos urbanos onde costuram as tramas das cidades, percorrem o Rio de Janeiro de uma ponta à outra da Baixada, de Duque de Caxias até Magé, constroem seus caminhos dentro de suas subjetividades, seja por escolha ou destino profissional, afetivo, pessoal.

Elas vivenciam essas cidades dentro dos contextos dos eventos culturais, vão e voltam de saraus, shows, cineclubes, trocam presenças e reflexões. Nem sempre essa circulação será fácil, apenas se dá de outra forma, de acordo com o seu desenho urbano, e levando em conta as questões de mobilidade e violência, o que faz desse ato de flanar como mulher pela Baixada um ato de resistência.

Se nos escritos anteriores o trabalho do flâneur era percorrer a cidade e narrar, aqui, flanar pela Baixada está muito mais ligado a fazer, a produzir, não somente observar, refletir sobre a cidade, nem caminhar lentamente, mas um "correr as cidades".

Uma questão que deve ser levada em consideração ao pensar o flanar da mulher pela Baixada é a violência de gênero. Segundo a $12^{a}$ edição do Dossiê Mulher (2020), formulado pelo Instituto de Segurança Pública (ISP, 2017), a Baixada Fluminense teve um total de 28.765 registros de violência contra a mulher no período, sendo 1.017 estupros, 9.324 casos de ameaças e 10.652 casos de lesão corporal dolosa. "O Dossiê Mulher 2017 mostra que as mulheres continuam sendo as maiores vítimas dos crimes de estupro $(85,3 \%)$, ameaça $(65,4 \%)$, lesão corporal dolosa $(63,8 \%)$, assédio sexual $(93,3 \%)$ e importunação ofensiva ao pudor $(91 \%)^{\prime \prime}$. Isso para mostrar apenas os dados computados; na realidade, muitos casos nem chegam a ser registrados.

A revista on-line Gênero e Número (Amanda PRADO, 2017) realizou uma pesquisa com muIheres que se deslocam pelas ruas da região metropolitana do Rio de Janeiro para mostrar como as mulheres se protegem de assédios e intimidações, e como essas ocorrências modificam, muitas vezes, seus caminhos. Os resultados da pesquisa da revista mostram que o assédio em locais públicos provoca um efeito direto nos padrões de mobilidade das mulheres pela cidade e as necessidades das mulheres ainda são pouco consideradas no planejamento urbano.

Andar na rua, para uma mulher, não é apenas o ato de andar. Existe uma série de pressões e intervenções externas, olhares, pessoas que se esbarram, que invadem o espaço do seu corpo, assédios. As ameaças sofridas pelos corpos femininos no espaço urbano, infelizmente, não são especificidades da Baixada Fluminense, existem em todas as partes do mundo. De acordo com Solnit (2016a): "Providências legais, costumes sociais aprovados tanto por homens quanto por mulheres, a ameaça implícita de assédio sexual e o estupro propriamente dito: tudo isso limita a capacidade das mulheres de andar onde e quando desejarem" (p. 388).

Andando pelas ruas da cidade, jovens mulheres são assediadas de maneiras que thes dizem que esse não é o mundo delas, a cidade delas, a rua delas; que a sua liberdade de circulação e associação pode ser prejudicada a qualquer momento; e que muitos estranhos esperam obediência e atenção delas. "Sorriam", um homem te ordena, e essa é uma maneira concisa de dizer que ele é o seu dono; ele é o chefe; você faz o que te dizem; seu rosto está lá para servir a vida dele, não expressar a sua própria. Ele é alguém; você não é ninguém (SOLNIT, 2016b).

Às questões apontadas por Solnit (2016) somam-se o racismo, a LGBTfobia, lesbofobia e transfobia que permeiam muitos dos espaços. Colocar nossos corpos nas ruas já é por si um ato de resistência, no sentido de que a permanência nesses espaços públicos que nos foram negados é uma forma de resistir. Produzimos, refletimos, circulamos, ocupamos e percebemos 
juntas quais são as nossas estratégias de viver essas cidades, dentro da sutileza de cada corpo. As estratégias que são usadas nesse flanar levam a crer que a mulher, a flâneuse da Baixada, resiste colocando-se na rua da cidade.

Foi no centro das cidades onde as mulheres foram empoderadas, mergulhando no coração das cidades, e caminhando onde elas não deveriam. Caminhando onde outras pessoas (homens) caminham sem provocar comentários. Esse é o ato transgressivo. Você não precisa passar por dificuldades ao usar botas impermeáveis para ser subversiva se você é uma mulher. Só caminhe para fora, pela porta de casa (ELKIN, 2016, p. 20, tradução nossa).

Flanar e resistir, o andar resistente pela Baixada, como mulher, não é negar essas condições, o medo da violência ao corpo, as questões da mobilidade urbana, mas construir estratégias por meio desses caminhos percorridos - seja circulando em grupos de mulheres, acompanhada por um parceiro ou uma parceira, ou se armando de artefatos que possam trazer certo conforto e segurança ao percurso, como facas e canivetes. Elas não deixam de ir e estar nos lugares da cidade, mas criam estratégias. Se o evento acaba muito tarde, voltam de Uber, dormem na casa de amigas, evitam ruas e caminhos mais conhecidos por relatos de violência.

Portanto, elas são permeadas por uma lógica de violência e mobilidade urbana que dificulta o caminhar, mas resistem, circulando na Baixada e criando eventos culturais que percorrem, envolvem, reconfiguram esse flanar, esse caminhar urbano e reflexivo, que não se dá somente no ócio e nem precisa estar em contato direto com a multidão. O desconhecido não é primordial para que a experiência sensível dos corpos femininos na cidade se consolide. As flanâncias dessas mulheres se dão no encontrar-se e não no perder-se constante de forma lenta; não é se afastar do familiar, mas buscá-lo. Não é ir de encontro com a alteridade, é respeitar a existência dela, mas buscar aquilo que as une como mulheres que percorrem caminhos e se aproximam no cenário cultural da Baixada Fluminense.

\section{Conclusão}

Neste artigo, pretendemos discutir as potencialidades de se pensar e pesquisar as mulheres nas ruas da cidade, a partir das possibilidades emergentes entre o ser mulher e ser flâneur e a generificação do conceito de flanar pela existência da figura da flâneuse. Utilizado desde o século XIX, o conceito de flanar tem sido aplicado a pesquisas sobre cidades, vida moderna e possibilidades de apropriação da vida urbana. Nesse sentido, uma pergunta recorrente ao longo da pesquisa foi: é possível pensar na flâneuse diante de diferentes contextos raciais e com foco nas mulheres de diversas classes sociais, de diferentes épocas? Outras indagações pertinentes foram: quais seriam as limitações de se denominar as mulheres da Baixada como flâneuses? E será que os conceitos e as experiências no amanhecer de uma Europa moderna dialogam com o que fazemos em países da América Latina como o Brasil?

"Correr as cidades" traduz de maneira mais aproximada a prática do que as mulheres interlocutoras da pesquisa fazem na Baixada Fluminense. Assim, elas herdam das flâneuses a possibilidade de estar ativamente nas cidades, nos espaços urbanos, e fazendo "seus corres". Mesmo que o corpo das mulheres seja afetado, ele não é afetado da mesma forma sempre, porque é necessário levar em consideração que raça, sexualidade e território muitas vezes se integram ao figurar o corpo da mulher na cidade.

Elkin afirma, no final de seu livro sobre as flâneuses, que o espaço não é neutro: "Espaço é uma questão feminista. O espaço que ocupamos - aqui na cidade, nós moramos na cidade - é constantemente refeito e desfeito, construído e questionado" (ELKIN, 2016, p. 286, tradução nossa). A autora cita Georges Perec (2008) sobre o espaço ser uma dúvida: "Eu devo constantemente marcá-lo, designá-lo. Nunca é meu, nunca me é dado, eu devo conquistá-lo" (ELKIN, 2016, p. 286, tradução nossa). Dessa maneira, a seu ver, de "Teerã a Nova lorque, de Melbourne a Mumbai, uma mulher ainda não pode andar na cidade da mesma maneira que um homem pode" (ELKIN, 2016, p. 286, tradução nossa). Segundo a autora,

[é] somente ao nos tornarmos cientes dos limites invisíveis da cidade que podemos desafiá-los. Uma flânerie feminina - a flâneuserie - não só muda o modo como nos movemos pelo espaço, mas intervém na organização desse mesmo espaço. Nós lutamos pelo nosso direito de perturbar a paz, de observar (ou não observar), de ocupar (ou não ocupar) e de organizar (ou desorganizar) o espaço nos nossos próprios termos (ELKIN, 2016, p. 288, tradução nossa).

Optar por um caminho mais movimentado em detrimento daquele menos movimentado, deixar de circular e ocupar espaços esvaziados, escuros, ou que dão medo, é contribuir com a lógica de que aquele espaço será cada vez mais vazio e tenebroso. Se todas evitam circular por uma região, a tendência é aquele local se tornar cada vez menos ocupado, cada vez menos ocupado por corpos femininos.

Elkin acredita que a flâneuse "ainda está lutando para ser vista, até mesmo agora, quando, como gostaríamos de pensar, ela de certa forma corre a cidade" (ELKIN, 2016, p. 18, tradução 
nossa). É importante observar aqui que, diferentemente do homem urbano de andar lento que originou os estudos das flanâncias, a flâneuse, mulher que caminha, corre a cidade.

Embora o que escrevessem fosse desautorizado, elas insistiam assim mesmo. Embora o que pintassem não recebesse reconhecimento, nutria a alma do mesmo jeito. As mulheres tinham de implorar pelos instrumentos e pelo espaço necessários às suas artes; e, se nenhum se apresentasse, elas abriam espaço em árvores, cavernas, bosques e armários (Clarissa ESTÉs, 1994, p. 8).

A flâneuse corre a cidade, ela comanda a cidade, ela se apropria da cidade. Pensar no direito das mulheres à cidade é um processo de (re)existência, de modos diferentes de existir, é um processo de criação de identidades, visto que, se refletirmos sobre a experiência brasileira, percebemos um país de vasto território, onde as experiências não apenas dependem das formas como estas diferentes cidades se constituem, assim como mulheres que são muito diferentes entre si as vivenciam. Aqui percebemos que correr a cidade também possibilita reinvenções, assim como um processo político que agrega múltiplas resistências, agendas e agências.

\section{Referências}

AKOTIRENE, Carla. Interseccionalidade. São Paulo: Pólen, 2019. (Coleção Feminismos Plurais - coord. Djamila Ribeiro)

BAUDELAIRE, Charles, "O pintor da vida moderna". In: BAUDELAIRE, Charles. Sobre a modernidade. São Paulo: Paz e Terra, 2001.

BENJAMIN, Walter. Passagens. Belo Horizonte: EDUFMG, 2006.

CERTEAU, Michel de. A invenção do cotidiano: artes de fazer. 22. ed. Petrópolis: Vozes, 2014.

CRENSHAW, Kimberlé. "Demarginalizing the intersection of race and sex: a black feminist critique of antidiscrimination doctrine, feminist theory and antiracist politics". University of Chicago Legal Forum, p. 139-167, 1989.

D'INCAO, Maria Ângela. "Mulher e família burguesa". In: DEL PRIORE, Mary (Org.); BASSANEZI, Carla (Coord. de textos). História das mulheres no Brasil. 10. ed. São Paulo: Contexto, 1997.

INSTITUTO DE SEGURANÇA PÚBLICA (ISP). Dados. DOSSIÊ Mulher 2017. Instituto de Segurança Pública, 2017. Disponível em hitp:///arquivos.proderi.ri.gov.br/isp imagens/Uploads/DossieMulher2017.pdf. Acesso em 28/04/2020.

ELKIN, Lauren. Flâneuse: women walk the city in Paris, New York, Tokyo, Venice, and London. New York: Farrar; Strausand Giroux, 2016.

ESTÉS, Clarissa Pinkola. Mulheres que correm com os lobos: mitos e histórias do arquétipo da muIher selvagem. Rio de Janeiro: Rocco, 1994.

FERREIRA, Gabriela Rizo. Deslocamentos e costuras com as mulheres da Baixada Fluminense: uma viagem à terra de muitas águas. 2018. Dissertação (Mestrado em Cultura e Territorialidades) Universidade Federal Fluminense, Rio de Janeiro, RJ, Brasil.

PRADO, Amanda. "Elas não se sentem livres". Gênero e Número, 2017. Disponível em http://www. generonumero.media/elas-nao-se-sentem-livres/. Acesso em 28/04/2020.

HOLLANDA, Heloísa Buarque de (Org.). Explosão feminista: Arte, cultura, política e universidade. São Paulo: Companhia das Letras, 2018.

JACQUES, Paola Berenstein. Elogio aos errantes. Salvador: EDUFBA, 2012.

KRACAUER, Siegfried. Jacques Offenbach and the Paris of his time. London: Constable, 1981.

MELLO, Luísa A. M. Mulheres, práticas de resistência cultural e ocupação simbólica: as flâneuses da Baixada. 2018. Dissertação (Mestrado em Educação, Cultura e Comunicação) - Universidade do Estado do Rio de Janeiro, Rio de Janeiro, RJ, Brasil.

MONNET, Nadja. "Flanâncias femininas e etnografia". Redobra, ano 5, n. 11, p. 218-234, 2014.

PEREC, George. Species of spaces. London: Penguin, 2008.

POLLOCK, Griselda. Vision and difference: femininity and the histories of art. London: Routledge, 1988. 
RIO, João do. A alma encantadora das ruas. Rio de Janeiro: Organização Simões, 1951.

ROBIN, Régine. Mégapolis: les derniers pas du flâneur. Paris: Stock, 2009. 397p.

ROLNIK, Raquel. "Territórios negros nas cidades brasileiras: etnicidade e cidade em São Paulo e no Rio de Janeiro". Estudos Afro-Asiáticos, Rio de Janeiro, n. 17, p. 29-41, set. 1989.

SCHUMAHER, Schuma; BRAZIL, Érico V. Mulheres negras no Brasil. São Paulo: Senac, 2007.

SISTEMA FIRJAN. Disponível em https://www.firjan.com.br/o-sistema-firjan/mapa-do-desenvolvimento. Acesso em 28/04/2020.

SOIHET, Rachel. "Mulheres pobres e violência no Brasil urbano". In: DEL PRIORE, Mary (Org.); BASSANEZI, Carla (Coord. de textos). História das mulheres no Brasil. 10. ed. São Paulo: Contexto, 1997.

SOLNIT, Rebecca. A história do caminhar. São Paulo: Martins Fontes, $2016 a$.

SOLNIT, Rebecca. "City of Women". The New Yorker, 2016b. Disponível em https://www.newyorker. com/books/page-turner/city-of-women. Acesso em 28/04/2020.

WILSON, Elizabeth. "O flâneur invisível". ArtCultura, Uberlândia, v. 15, n. 27, p. 43-63, jul.-dez. 2013.

WILSON, Elizabeth. The sphinx in the city: urban life, the control of disorder, and women. Berkeley and Los Angeles: University of California Press, 1992.

WOLFF, Janet. "The invisible flâneuse: women and the literature of modernity". Theory, Culture \& Society, v. 2, n. 3, p. 37-46, nov. 1985.

Luísa Antonitsch Mansilha Mello (luisa.mello@sescrio.org.br) é produtora cultural, crítica de cinema e mestre pelo Programa de Pós-Graduação em Educação, Cultura e Comunicação em Periferias Urbanas (PPGECC), Universidade do Estado do Rio de Janeiro.

Ana Paula Pereira da Gama Alves Ribeiro (ana.ribeiro@ueri.br) é antropóloga, doutora em Saúde Coletiva. Professora Adjunta da Faculdade de Educação da Baixada Fluminense e do Programa de Pós-Graduação em Educação, Cultura e Comunicação em Periferias Urbanas (PPGECC), Universidade do Estado do Rio de Janeiro. 


\section{COMO CITAR ESSE ARTIGO DE ACORDO COM AS NORMAS DA REVISTA}

MELLO, Luísa Antonitsch Mansilha; RIBEIRO, Ana Paula Pereira da Gama Alves. "Circulação e vivência nas cidades: ser mulher, ser flâneuse". Revista Estudos Feministas, Florianópolis, v. 29, n. 1, e67152, 2021.

\section{CONTRIBUIÇĀO DE AUTORIA}

Este artigo é originado da dissertação de mestrado de Luísa Antonitsch Mansilha Mello, que concebeu o tema em diálogo com a orientação, coletou os dados, elaborou e redigiu o manuscrito a partir da discussão dos resultados.

Ana Paula Alves Ribeiro orientou o trabalho e estabeleceu diálogo na concepção do tema, na coleta de referências junto à Luísa Antonitsch, discutiu os resultados e redigiu parte do texto que consta neste artigo final.

A versão original deste artigo foi traduzida para o inglês por Jeffrey Hoff (jeffhoff@floripa.com.br).

\section{FINANCIAMENTO}

O presente trabalho foi realizado com apoio da Coordenação de Aperfeiçoamento de Pessoal de Nível Superior - Brasil (CAPES) - Código de Financiamento 001

\section{CONSENTIMENTO DE USO DE IMAGEM}

Não se aplica.

\section{APROVAÇĀO DE COMITÊ DE ÉTICA EM PESQUISA}

Não se aplica.

\section{CONFLITO DE INTERESSES}

Não se aplica.

\section{LICENÇA DE USO}

Este artigo está licenciado sob a Licença Creative Commons CC-BY 4.0 International. Com essa licença você pode compartilhar, adaptar, criar para qualquer fim, desde que atribua a autoria da obra.

\section{HISTÓRICO}

Recebido em 21/08/2019

Reapresentado em 06/05/2020

Aprovado em 29/06/2020 